\title{
Non-Posterior Subtraction Osteotomy Surgery to Restore Lumbar Lordosis in the Hidden Sagittal Imbalance of the Adult Degenerative Spine Alessandro Ramieri ${ }^{1 *}$, Massimo Miscusi², Filippo Maria Polli², Antonino Raco ${ }^{2}$, Giuseppe Costanzo ${ }^{3}$
}

${ }^{1}$ Department of Orthopaedics, Don Gnocchi Foundation ONLUS, Milan, Italy

${ }^{2}$ Department of Neurosurgery, S. Andrea Hosp Sapienza, Rome University, Italy

${ }^{3}$ Department of Orthopaedics, Polo Pontino Sapienza, Rome University, Italy

\begin{abstract}
Purpose: Sagittal imbalance of severe adult degenerative deformities requires surgical correction to improve pain, mobility and quality of life. Our aim was a harmonic and balanced spine, treating a series of adult degenerative kyphoscoliosis by a nonposterior subtraction osteotomy technique. Extreme lateral (XLIF) and transforaminal (TLIF) interbody fusion were used to restore lumbar lordosis and mobilize the coronal curve, while grade 2 osteotomy (SPO) was useful to further decrease kyphosis.
\end{abstract}

Methods: We operated 22 thoraco-lumbar and lumbar degenerative deformities, characterized by a sagittal compensated (hidden) imbalance (SVA $<50 \mathrm{~mm}$ ), with or without coronal deformity, and distinguished according to the SRS-Schwab classification. All patients were submitted to X-ray screening during pre, post-operative and follow-up periods.

Results: Mean age was 65.3 (50-74; M/F 1: 4). Sixteen deformities were type $L$ and 6 type N. Loss of LL was moderate (+) in 14 cases and marked (++) in 8 . We performed 39 XLIFs, 8 TLIFs, 32 SPOs. Complication rate was minimal. Pelvic tilt, lumbar lordosis, sagittal vertical axis and thoracic kyphosis improved $(p<0.05)$, post-operative values were similar to those pre-operatively calculated in $90 \%$ of cases and clinical follow-up (mean 20.5; range 1824), scored using VAS and ODI, was satisfactory in all cases, except for two due to sacro-iliac pain.

Conclusion: Current follow-up does not allow definitive conclusions. However, the surgical approach reported seems to be a viable choice usable in these compensated adult deformities, avoiding risks and complications of more aggressive pedicle subtraction osteotomies.

Keywords: Degenerative spine; Sagittal imbalance; Spinal surgery

\section{Introduction}

Over the past two decades, there has been an increasing recognition of the importance of the sagittal balance restoration in the surgical treatment of adult spine degenerative deformities [1,2]. Normal aspect of the spinal sagittal profile have been described on asymptomatic patients, measuring the reciprocal curves of thoracic kyphosis (TK) and lumbar lordosis (LL), and the relationship between pelvis and spine, described as spino-pelvic parameters [3]. In pathological conditions, as degenerative diseases, modifications of these parameters have been directly related to back pain and dysfunction [4]. Surgical correction of severe and rigid sagittal imbalances, essentially characterized by lumbar hypolordosis up to kyphosis and retroversion of the pelvis, is feasible through surgical techniques such as the posterior subtraction osteotomy (PSO) and the posterior vertebral column resection (PVCR) $[5,6]$. Nevertheless, these techniques may expose patients to a high incidence of short-term complications, up to 30\% [7], overcorrection [8] and different patterns of mechanical failures [9]. The anterior column realignment (ACR) can be an alternative procedure, based on the complete release of the anterior longitudinal ligament, which has been recently introduced to effectively restore lordosis, as the PSO, but with less risks of complications [10,11]. Aforementioned surgical procedures to treat severe lumbar sagittal and/or coronal deformities, associated to spinal rigidity, have been extensively reported in literature. In particular, according to Berjano-Lamartina classification [12], they seem absolutely required for uncompensated deformities that have the sagittal vertical axis (SVA) $>50 \mathrm{~mm}$. We hypothesized that into those deformities, generally more flexible, which maintain an SVA $<50 \mathrm{~mm}$ by means of the activation of compensatory mechanisms [13], less aggressive surgical approaches may be proposed. So, according to this setting, a series of 22 consecutive adult patients presenting lumbar or thoraco-lumbar degenerative painful deformities, characterized by a compensated sagittal imbalance, have been treated by multilevel
XLIFs, TLIFs and multiple Grade 2 posterior osteotomies [14]. When it needed, posterior decompression have been obtained to treat stenosis. Radiological and clinical data have been recorded at a minimum of eighteen months follow-up. In other words, opposing to PSO, we propose a less aggressive, targeted surgical approach in selected cases of degenerative adult sagittal misalignment, characterized by the activation of some compensatory mechanisms that generate pain and discomfort, but make these deformities less severe than those entirely unbalanced.

\section{Materials and Methods}

Twenty-two adult patients affected by degenerative lumbar and thoraco-lumbar deformities were prospectively and consecutively enrolled for the present study. They suffered for back and/or radicular pain, with or without claudication, unresponsive to conservative therapy, based on bed rest, painkillers, brace and/or postural rehabilitation, for at least 6 months. They did not present severe general comorbidities or hip diseases. All patients were submitted to radiological protocol based on full length postero-anterior and lateral standing $\mathrm{x}$-rays and MRI. Lateral bending and supine position projections completed the pre-operative study to establish flexibility of the spine. Deformities

*Corresponding author: Alessandro Ramieri, MD, PhD, Don Gnocchi Foundation, ONLUS, Via M. Caviglia 30, Rome, Italy, Tel: +39 02 40308910; Fax +390633086412; E-mail: alexramieri@libero.it

Received June 07, 2016; Accepted June 23, 2016; Published June 25, 2016

Citation: Ramieri A, Miscusi M, Polli FM, Raco A, Costanzo G (2016) NonPosterior Subtraction Osteotomy Surgery to Restore Lumbar Lordosis in the Hidden Sagittal Imbalance of the Adult Degenerative Spine. J Spine 5: 315 doi:10.4172/2165-7939.1000315

Copyright: ( 2016 Ramieri A, et al. This is an open-access article distributed under the terms of the Creative Commons Attribution License, which permits unrestricted use, distribution, and reproduction in any medium, provided the original author and source are credited. 
Citation: Ramieri A, Miscusi M, Polli FM, Raco A, Costanzo G (2016) Non-Posterior Subtraction Osteotomy Surgery to Restore Lumbar Lordosis in the Hidden Sagittal Imbalance of the Adult Degenerative Spine. J Spine 5: 315. doi:10.4172/2165-7939.1000315

were classified on the basis of SRS-Schwab Adult Spinal Deformity classification [15]. Nineteen thoraco-lumbar kyphoscoliosis with primary sagittal imbalance and 3 post-surgical lumbar kyphosis with secondary sagittal imbalance were identified. All patients showed a "compensated (hidden) deformity", labeled by an SVA $<50 \mathrm{~mm}$ and increased pelvic tilt (PT) more than 20 degrees or pathological femoral shaft axis [16]. Decision-making process was established on the basis of spino-pelvic parameters, coronal aspect of the deformity and severity of clinical disorders. Surgery was proposed when Oswestry Disability Index (ODI) and Visual Analogue Scale (VAS) respectively exceeded 50 percent and score 6 .

According to literature data [15,17], to improve patient's impairment, the aim of our surgery was to achieve the following postsurgical sagittal values: - $\mathrm{PT}<20^{\circ}$; - pelvic incidence (PI) - LL mismatch within $10^{\circ}$; - TK $<$ PI; - SVA $<25 \mathrm{~mm}$. Two-stages surgery was adopted: the first mininvasive stage resulted in the multilevel extreme lateral interbody fusion (XLIFs), via transpsoas approach, by a $10^{\circ}$ lordotic cages. The second stage included transforaminal lumbar interbody fusion (TLIF) at L4-L5 and/or L5-S1 and posterior instrumented arthrodesis with pedicle screws. Two or 3 Smith-Petersen osteotomies (SPOs) were performed when an higher correction of lordosis was needed (from 8 to $10^{\circ}$ for level) and posterior decompression of the spinal canal was obtained in case of segmental stenosis. During the follow-up period, patients were submitted to full-spine standing $\mathrm{x}$-rays performed at 3, 6, 12, 18 and 24 months. Visual analogue scale (VAS) and Oswestry Disability Index (ODI) were recorded and compared with those before surgery. Data analysis was conducted using the paired $t$ test and the Wilcoxon test to compare results within the group and changes from baseline. Statistical significance was defined as $p<0.05$.

\section{Results}

Mean age was 65.3 (50-74) with sex ratio M/F 1: 4. Sixteen deformities were type L and 6 type N. PI minus LL mismatch was moderate (between 10 and 20 degrees) in 14 cases and marked (more than 20 degrees) in 8 (Figure 1). Mean pre-op global alignment (SVA) was $34 \mathrm{~mm}$ (range 20-48) and mean PT $27.7^{\circ}$ (range 22-35). XLIFs were 39 and TLIFs 8 . The upper instrumented vertebra (UIV) was T10

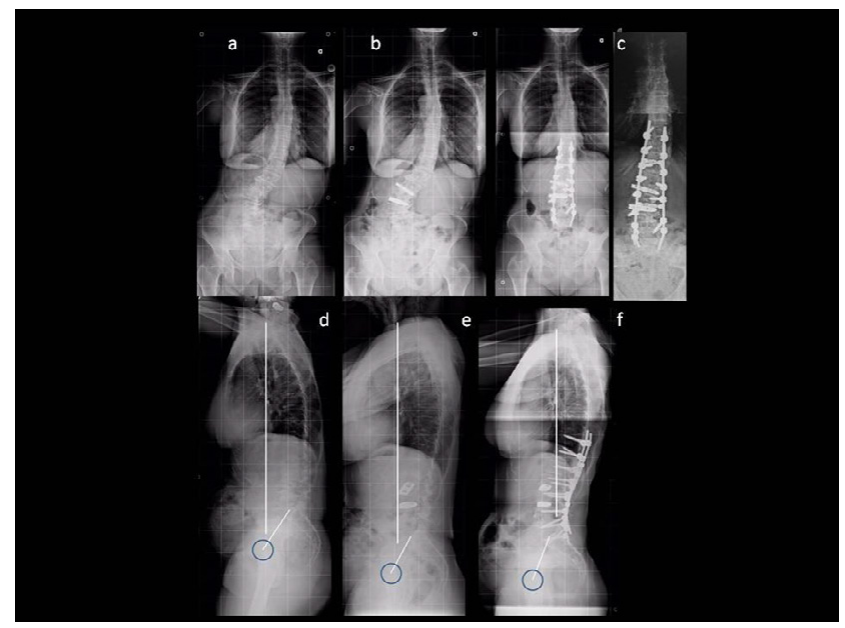

Figure 1: Type $\mathrm{L}++$ deformity in a 65 yr-old female. (a) Pre-operative scoliosis $\left(36^{\circ}\right)$ with coronal imbalance; (b) After XLIFs, improvement up to $30^{\circ}$; (c) Posterior T11-S1 fixation, L4-L5 TLIF and L3-L4 and L4-L5 SPOs. Residual scoliosis was $<10^{\circ}$ (d) Sagittal preoperative parameters: SVA $=48 \mathrm{~mm} ; \mathrm{PT}=35^{\circ}$ PI $67^{\circ} ; \mathrm{LL}=27^{\circ}$; PI-LL=40 ; (e) After XLIFs, PT decreased to $29^{\circ}$ and SVA to $40 \mathrm{~mm}$; (f) Two years after surgery, we recorded the following values: SVA $=0^{\circ}$, $\mathrm{PT}=18^{\circ}, \mathrm{LL}=58^{\circ}$ and $\mathrm{PI}-\mathrm{LL}=9^{\circ}$.

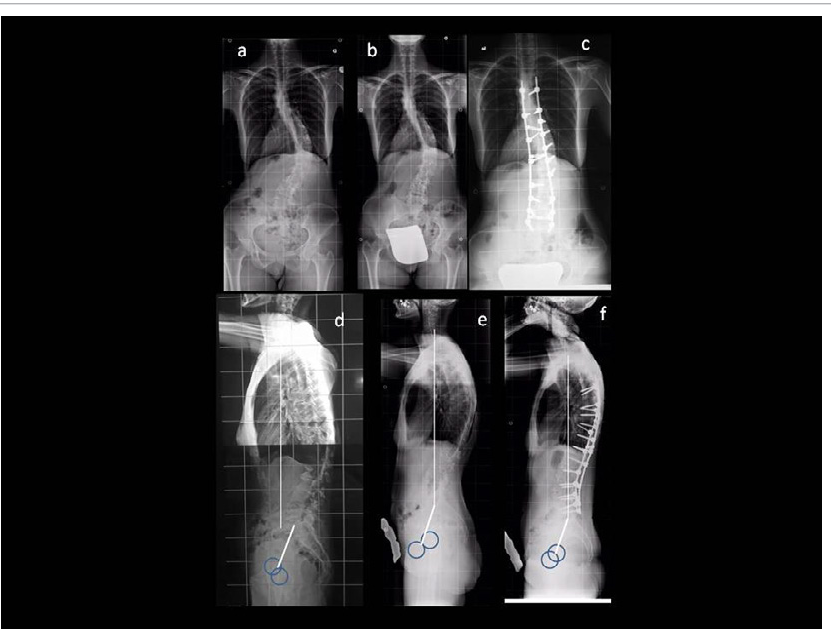

Figure 2: Type $L+$ deformity in a 51 ysr old female. (a) Coronal deformity with value of $48^{\circ}$; (b) Improvement up to $36^{\circ}$ after 3 XLIFs; (c) T6-L5 posterior fixation plus L4-L5 TLIF and 2 SPOs. Residual scoliosis was $18^{\circ}$ eighteen months after surgery; (d) Sagittal pre-operative values: $\mathrm{SVA}=47 \mathrm{~mm} ; \mathrm{PT}=30^{\circ} ; \mathrm{PI}=50^{\circ}$; $\mathrm{LL}=32^{\circ}$; $\mathrm{PI}-\mathrm{LL}=18^{\circ}$; (e) Changes from the baseline after XLIFs: SVA=20 mm; $\mathrm{PT}=22^{\circ}$; LL $=44^{\circ}$; (f) At follow-up, SVA was $5 \mathrm{~mm}, \mathrm{PT} 16^{\circ}$, LL $50^{\circ}$ and PI-LL $=0^{\circ}$.

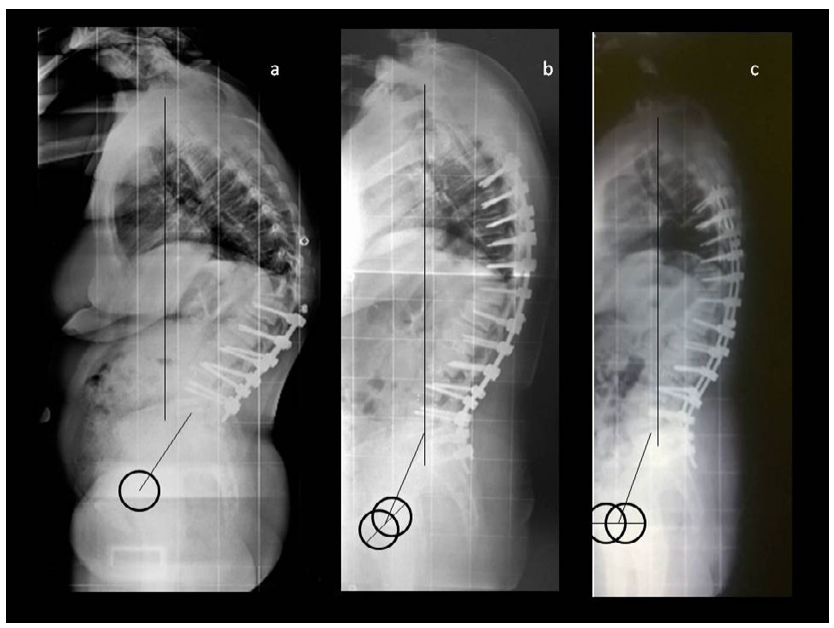

Figure 3: Secondary sagittal deformity type $\mathrm{N}++$ treated by 2 XLIFs, 5 PSOs and T7-S2 posterior fixation. (a) Pre-operatively, SVA $=46 \mathrm{~m}$ and $\mathrm{PT}=36^{\circ}$; (b) Immediately after surgery, SVA improved up to $24 \mathrm{~mm}$ and PT was $23^{\circ}$; (c) At 2 years follow -up, SVA was $20 \mathrm{~mm}$ and PT $19^{\circ}$.

in 10 cases, T11 in 9, L2 in 1, T6 (Figure 2) or T7 in the residual 2 cases. The lower instrumented vertebra (LIV) was 14 times S1, 4 S2 (Figure 3), $3 \mathrm{~L} 5$ and $1 \mathrm{~L} 4$. Thirty-two SPOs were performed at min. 2-max 5 levels (mean 2.9). No major peri-operative complications or permanent neurological injuries were observed. Complication rate was $18 \%(7 / 39)$ for XLIFs and $22.7 \%$ (5/22) for posterior surgeries. XLIFrelated complications were 1 pleural tear, 1 retroperitoneal hematoma, 2 transient quadriceps weaknesses, 3 transient psoas weakness. After posterior surgery, we recorded 2 cases of severe anemia, 1 case of inferior leg phlebitis, 1 case of transient radicular pain. One female showed a monolateral scapolo-humeral decompensation at 1 mouth after surgery due to temporary long thoracic nerve palsy. At FU (range 1824 mo; mean 20.5), we recorded no mobilization, junctional syndromes or infections. Postoperative changes of spino-pelvic parameters were summarized in Tables 1 and 2. After anterior surgery, improvements were recorded but without statistical significance $(p>0.05)$. After posterior surgery, mean PI-LL decreased from $16^{\circ}$ (range 12-28) to $7^{\circ}$ postoperatively (range $0-10$ ) and $9^{\circ}$ (range $0-13$ ) at the final follow- 
Citation: Ramieri A, Miscusi M, Polli FM, Raco A, Costanzo G (2016) Non-Posterior Subtraction Osteotomy Surgery to Restore Lumbar Lordosis in the Hidden Sagittal Imbalance of the Adult Degenerative Spine. J Spine 5: 315. doi:10.4172/2165-7939.1000315

Page 3 of 5

\begin{tabular}{|c|c|c|c|c|c|}
\hline \multicolumn{1}{|c|}{ Pts=22; 39 Xlifs } & Mean SVA & Mean PT & \multicolumn{2}{|c|}{ Mean PI-LL } & \multicolumn{2}{|c|}{ Mean Cobb } \\
\hline Spino-pelvic parameters (mean) & & $27.7^{\circ}$ & $16^{\circ}$ & $33^{\circ}$ \\
\hline Pre-op & $34 \mathrm{~mm}$ & $21.8^{\circ}$ & $12^{\circ}$ & $37^{\circ}$ \\
\hline Post-op & $23 \mathrm{~mm}$ & $\mathrm{p}=0.41$ & $\mathrm{p}>0.05$ & $27^{\circ}$ \\
\hline P value & $\mathrm{p}>0.05$ & $\mathrm{P}>0.05$ & \\
\hline
\end{tabular}

Table 1: Changes from baseline of spino-pelvic parameters after multilevel XLIFs.

\begin{tabular}{|c|c|c|c|c|c|c|c|c|c|c|c|c|}
\hline Pts $=22$ & Mean SVA & Mean PT & Mean PI-LL & Mean TK & Mean Cobb & Th & L1-L2 & L2-L3 & L3-L4 & L4-L5 & L5-S1 & S2 \\
\hline \multicolumn{13}{|c|}{ Spino-pelvic parameters } \\
\hline Pre-op & $34 \mathrm{~mm}$ & $27.7^{\circ}$ & $16^{\circ}$ & $33^{\circ}$ & $37^{\circ}$ & - & - & - & - & - & - & - \\
\hline Post-op & $15 \mathrm{~mm}$ & $12^{\circ}$ & $7^{\circ}$ & $42^{\circ}$ & $17^{\circ}$ & - & - & - & - & - & - & - \\
\hline FU & $18 \mathrm{~mm}$ & $13^{\circ}$ & $9^{\circ}$ & $45^{\circ}$ & $19^{\circ}$ & - & - & - & - & - & - & - \\
\hline$P$ value & 0.034 & 0.027 & 0.041 & 0.030 & 0.021 & - & - & - & - & - & - & - \\
\hline \multicolumn{13}{|c|}{ Implants and techniques } \\
\hline XLIFs & - & - & - & - & - & 2 & 6 & 14 & 17 & - & - & - \\
\hline TLIFs & - & - & - & - & - & 1 & 1 & & - & 5 & 1 & - \\
\hline SPOs & - & - & - & - & - & 3 & 3 & 6 & 8 & 12 & - & - \\
\hline UIV & - & - & - & - & - & 22 & - & - & - & - & - & - \\
\hline LIV & - & - & - & - & - & - & - & - & - & 1 & 17 & 4 \\
\hline
\end{tabular}

Table 2: Changes from baseline of spino-pelvic measurements after two stages surgery adopted in 22 adult thoraco-lumbar and lumbar "compensated" deformities. Type of implants and techniques are reported in detail.

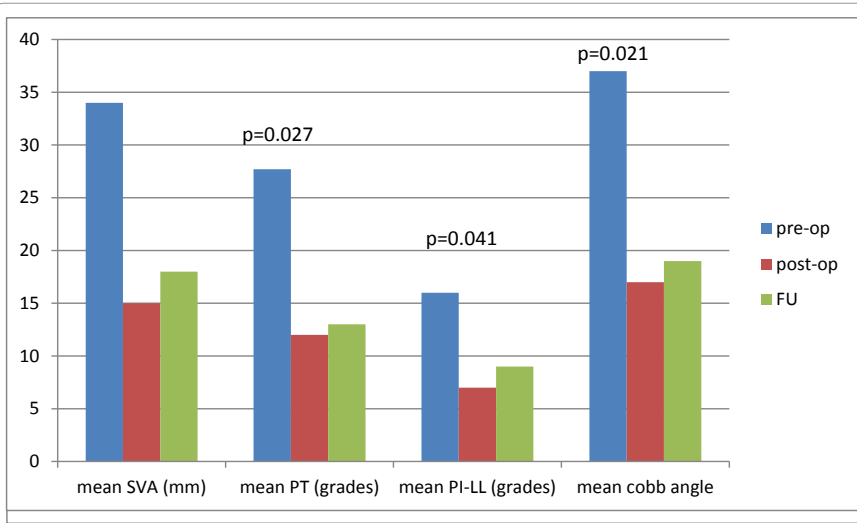

Figure 4: Spino-pelvic parameters: changes from baseline to follow-up.

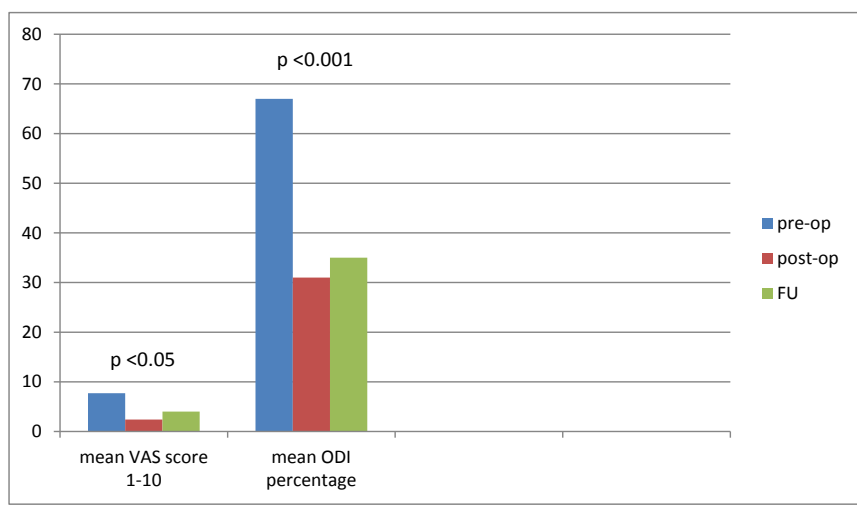

Figure 5: Clinico-functional parameters: change from baseline to follow-up.

up. Post-operative SVA was on average $15 \mathrm{~mm}$ (range 5-22) and 18 $\mathrm{mm}$ (range 8-25) at follow-up, while PT decreased from baseline to $12^{\circ}$ (range 10-23) and $13^{\circ}$ (range 12-23) in the postoperative and followup periods. Overall, we observed that final postoperative sagittal values were similar to those preoperatively estimated in 20 cases (91\%). All changes from baseline parameters were statistically significant after two-stage surgery $(\mathrm{p}<0.05)$ (Figure 4$)$.

Mean preoperative VAS was 7.7 (range 6-10), while ODI was 67\% on average (range 50-78). Postoperatively, VAS and ODI decreased respectively to 2.4 (range $2-4$ ) and $31 \%$ (range 25-45), while their values were 4 (range 2-6) and 35\% (range 20-55) at final follow-up. All changes of these clinical parameters were significant if compared to baseline $(\mathrm{p}<0.05)$ (Figure 5).

\section{Discussion}

Adult spine degenerative deformity can be divided into coronal (scoliosis), sagittal (kyphosis) and mixed. Balanced or imbalanced scoliosis with lateral shift less than $40 \mathrm{~mm}$ seems to have little clinical and functional consequences [2,4]. Contrarily, both compensated and uncompensated sagittal imbalance is correlated with poorer quality of life in the general population and mediocre outcomes in surgical patients [15]. In fact, an ideal spinal alignment allows an individual to assume standing posture with minimal muscular energy expenditure [18]. Increase positive sagittal imbalance results in increased muscular effort and energy expenditure causing pain, fatigue and disability. Our series considered patients affected by a painful "compensated sagittal deformity", defined as SVA $\leq 50 \mathrm{~mm}$, increased PT and/or variation of femoral shaft axis [16], different grades of scoliosis and loss of LL, responsible for intractable back and/or radicular pain and functional disability. In these morphological and clinical conditions, the goals of surgery should be to obtain improvement of PT and LL, symptoms relief and solid fusion $[19,20]$. Different surgical approaches and techniques were proposed: PSO technique seems to correct gross uncompensated fixed deformity on both plans, but risks associated are quite high; ACR procedure seems to have good ability to restore lumbar profile, almost as PSO, but with lower risks. However, surgical treatment of pathological loss of LL in the setting of SVA achieves similar improvement as surgical treatment for elevated SVA [21].

Approaching a consecutive series of degenerative compensated lumbar and thoraco-lumbar deformities, we proposed and applied an alternative procedure based on the ability of multilevel XLIFs to improve sagittal and coronal alignment [22], associated with posterior screw fixation, grade 2 osteotomies to achieved more lordosis and TLIFs in L4-L5 and/or L5-S1, levels at risk or not reachable, in our experience, with direct minimally invasive lateral access. Decompressive surgery was associated to treat spinal stenosis. XLIF and TLIF were usually used to obtain lumbar interbody fusion. In this series, we performed 
targeted XLIFs and TLIFs to achieve three main goals: - intervertebral fusion; - coronal curve mobilization; - lumbar lordosis restoration. Radical discectomy and osteophytectomy were useful to mobilize the apex of rigid deformity, while lateral lordotic cage can significantly improve the lordosis of the lumbar or thoraco-lumbar spine.

The surgical planning was primarily decided on the basis of preoperative evaluation of sagittal imbalance. According to literature $[15,17]$, we considered, to achieve the spine into balance, $\mathrm{PT}<20^{\circ}$, PI$\mathrm{LL} \leq 10^{\circ}$ and $\mathrm{TK}<\mathrm{PI}$. Our procedure was based on two-stage surgery, with multilevel XLIFs as the first stage. Advantages of XLIF in terms of peri-operative outcomes and complications were known [23]. Recently, this surgical strategy was also described by Hsieh et al. [24] that, in a series operated by two-stage combined approach, reported a significant improvement of sagittal and coronal deformity after a multilevel anterior lumbar interbody fusion. In our hands, multilevel XLIFs by use of lordotic cages, inserted after breakage of osteophytes and mobilization of the apex, were be able to decrease PI-LL mismatch, $\mathrm{PT}$ and scoliosis even if changes were not so relevant. Two-weeks later, we re-calculated spino-pelvic parameters on new full length x-ray films, to detect more appropriate levels to be treated by TLIFs and SPOs. Final improvements of spino-pelvic parameters were statistically significant after second stage posterior surgery.

In our series, the UIV most used was T10 or T11. The LIV ranged from L4 to S2, with greater frequency in S1. There is no consensus on the best UIV or LIV to be adopted. About the UIV, outcomes from recent papers published by the International Spine Study Group (ISSG) seem conflicting. Kim et al. [25] emphasizes that upper thoracic and lower thoracic instrumented vertebrae achieve same results in terms of clinical complications. Recently, Sheer et al. [26] reported that the upper thoracic seems to maintain correction better than lower thoracic at 2 years follow-up. Nevertheless, Fukumejad et al. clinical study [27] shows that the upper thoracic is more effective than the lower only for the SRS-22 self-image score. Even so, with regard to our choices, we did not observe proximal junction failure (PJK) or pain above the instrumentation at two years follow-up.

The choice of the LIV in adult scoliosis has been a subject of debate in the past decades [28-30] and controversies still exist. Actually, spine surgeons select the LIV on the basis of personal experiences and preferences: therefore, in this study, our personal choice did not consider the pelvic fixation as distal foundation. Bao et al. [31] indicates that the unfused disc below the LIV may contribute to the improvement in the coronal balance, while the LIV in S1 or the pelvic fixation could be potential risk factors for persistent coronal imbalance, particularly in patients with SPOs. In the surgical series reported by Kuhns et al. [30], that had the LIV in L5, L5-S1 degenerative diseases were frequently observed during the first 5 up to 15 years follow-up. Berjano et al. [16] and more recently Koller et al. [32] suggested that an insufficient distal foundation could be one factor influencing failure and so they advocated an advanced lumbo-sacral fixation, including the pelvic fixation. On the contrary, Guler and the European Spine Study Group [33] underlined the high risk of failures of the pelvic fixation in older patients, up to $35 \%$. Our choice of the LIV was influenced by the condition of the L5-S1 disk, age of patient and quality of bone during screwing. In patients older than 65 years, with severe L5-S1 degenerative changes, we always preferred $S 1$ as distal anchorage, using bi-cortical screws with diameter 7-7.5 mm, or S2 as advanced fixation if very poor bone quality was intra-operatively detected. In the others, distal fixation included more frequently L5. Actually, we did not recorded distal mechanical failures, but only two cases of sacro- iliac pain and, in our hands; coronal balance did not worsened by the association between multilevel SPOs and S1 anchorage.

Comparing three or more SPOs to one PSO, correction of the kyphosis may be nearly identical [31,34]. We applied SPO to obtain a higher recovery of the LL. Considering, for example, a loss of LL of about $40^{\circ}$ : we could calculate that, by means of 2 XLIFs and 2 or 3 SPOs, this improvement is possible. However, by this pure mathematical approach, the risk that the post-operative condition is different from the postulated one exists. Infact, Moal et al. [35] reported a percentage of failure of the pre-operative planning up to $40 \%$. We observed a poor correction in 6 cases (27\%), 4 (18\%) on the coronal plane and $2(9 \%)$ on the sagittal plane.

No severe complications were recorded. Complication rate was similar for XLIFs and posterior surgery. No neurological damages were recorded, probably also for the continuous use of intraoperative neuromonitoring.

On the clinical point of view, we evaluated our patients by visual analogue scale (VAS) and Oswestry Disability Index (ODI) that, as reported in a very recent meta-analysis [36], are the parameters mainly applied in literature. We recorded the significant improvement of pain and disability scores in all patients, but two of them (9\%), with LIV in S1, suffered for a sacro-iliac pain. We can speculate an extension to the pelvis if the pain will not improve by conservative treatments.

\section{Conclusion}

Adult scoliosis with sagittal misalignment is a condition that decreases function and quality of life. Surgical correction of the spine deformity allows clinical improvements. In recent years, there have been major surgical advances in the treatment of sagittal imbalance and studies outlining new ideas that can inspire further research. Especially, different techniques of posterior vertebral osteotomy and anterior fusion by direct lateral approach have become widely used. Satisfactory SVA is strongly correlated with the improvement of LL and PT that can be calculated pre-operatively. PSO or multiple SPOs seem to be able to correct kyphosis without significant difference. We applied SPOs with multilevel XLIFs and TLIFs to obtain anterior fusion, but also to mobilize the deformity and restore an optimal lordosis with an adequate $\mathrm{PT}$ in a series of painful and disabling adult spine imbalances classified as compensated sagittal deformities. Posterior fixation with pedicular screws was mainly realized including T10/T11-S1 levels. When it needed, advanced lumbo-sacral fixation was achieved by S2 anchorage. No major vascular or neurological damage were observed. At two years follow-up we did not recorded mechanical failures and no revision surgery was required. Clinically, pain and functional scores improved, except in two cases suffering from sacro-iliac pain. With the limitations of this study, related to the follow-up and the small number of patients enrolled, we propose multilevel targeted XLIFs, TLIFs and SPOs, alternative to more aggressive and dangerous PSO or PVCR, to correct loss of lordosis in such deformities with an SVA $<50 \mathrm{~mm}$. Further controls will be needed to detect proximal or distal mechanical complications and the possible rate of revision surgery.

\section{References}

1. Aebi M (2005) The adult scoliosis. Eur Spine J 14: 925-948.

2. Glassman SD, Bridwell K, Dimar JR, Horton W, Berven S, et al. (2005) The impact of positive sagittal balance in adult spinal deformity. Spine (Phila Pa 1976) 30: 2024-2029.

3. Mac-Thiong JM, Roussouly P, Berthonnaud E, Guigui P (2010) Sagitta parameters of global spinal balance: normative values from a prospective cohort of seven hundred nine Caucasian asymptomatic adults. Spine 35: E1193-1198. 
Citation: Ramieri A, Miscusi M, Polli FM, Raco A, Costanzo G (2016) Non-Posterior Subtraction Osteotomy Surgery to Restore Lumbar Lordosis in the Hidden Sagittal Imbalance of the Adult Degenerative Spine. J Spine 5: 315. doi:10.4172/2165-7939.1000315

4. Glassman SD, Berven S, Bridwell K, Horton W, Dimar JR (2005) Correlation of radiographic parameters and clinical symptoms in adult scoliosis. Spine (Phila Pa 1976) 30: 682-688.

5. Bridwell KH, Lewis SJ, Rinella A, Lenke LG, Baldus C, et al. (2004) Pedicle subtraction osteotomy for the treatment of fixed sagittal imbalance. Surgical technique. J Bone Joint Surg Am 86-86A Suppl 1: 44-50.

6. Suk SI, Chung ER, Lee SM, Lee JH, Kim SS, et al. (2005) Posterior vertebral column resection in fixed lumbosacral deformity. Spine (Phila Pa 1976) 30 : E703-710.

7. Charosky S, Guigui P, Blamoutier A, Roussouly P, Chopin D (2012) Study Group on Scoliosis: Complications and risk factors of primary adult scoliosis surgery: A multicenter study of 306 patients. Spine (Phila Pa 1976) 37: 693-700.

8. Blondel B, Schwab F, Bess S, Ames C, Mummaneni PV, et al. (2013) Posterior global mal-alignment after osteotomy for sagittal plane deformity: It happens and here is why. Spine (Phila Pa 1976) 38: E394-401.

9. Maier S, Smith JS, Schwab F, Obeid I, Mundis G, et al. (2014) Revision surgery after three-column osteotomy in 335 adult spinal deformity patients: Intercenter variability and risk factors. Spine.

10. Berjano $P$, Cecchinato $R$, Sinigaglia A, Damilano M, Ismael MF, et al. (2015) Anterior column realignment from a lateral approach for the treatment of severe sagittal imbalance: a retrospective radiographic study. Eur Spine J 24: 433-438.

11. Turner JD, Akbarnia BA, Eastlack RK, Bagheri R, Nguyen S, et al. (2015) Radiographic outcomes of anterior column realignment for adult sagittal plane deformity: a multicenter analysis. Eur Spine J 24 Suppl 3: 427-432.

12. Berjano P, Lamartina $C$ (2014) Classification of degenerative segment disease in adults with deformity of the lumbar or thoracolumbar spine. Eur Spine J 23 : 1815-1824.

13. Barrey C, Roussouly P, Le Huec JC, D’Acunzi G, Perrin G (2013) Compensatory mechanisms contributing to keep the sagittal balance of the spine. Eur Spine $J$ 22 Suppl 6: S834-841.

14. Schwab F, Blondel B, Chay E, Demakakos J, Lenke L, et al. (2014) The comprehensive anatomical spinal osteotomy classification. Neurosurgery 74 : 112-120

15. Schwab F, Ungar B, Blondel B, Buchowski J, Coe J, et al. (2012) Scoliosis Research Society: Schwab adult spinal deformity classification: A validation study. Spine 37: 1077-1082.

16. Berjano P, Bundy J, Balsano M (2013) Spinal alignment and correction in adults. In: Goodrich A, Volcan IJ (eds), Extreme lateral interbody fusion (XLIF) 91-115.

17. Savage JW, Patel AA (2014) Fixed sagittal plane imbalance. Global Spine J 4: 287-296.

18. Dubousset J (1994) Three-dimensional analysis of the scoliotic deformity In: Weinsteid SL (ed) The Pediatric Spine: Principles and practice. New York Raven Press.

19. Heary RF, Kumar S, Bono CM (2008) Decision making in adult deformity. Neurosurgery 63: 69-77.

20. Birknes JK, White AP, Albert TJ, Shaffrey Cl, Harrop JS (2008) Adult degenerative scoliosis: a review. Neurosurgery 63: 94-103.

21. Smith J, Singh M, Klineberg E, Shaffrey Cl, Lafage V, et al. (2014) Surgica treatment of pathological loss of lumbar lordosis (flatback) in the setting of normal SVA achieves similar clinical improvement as surgical treatment for elevated SVA. J Neurosurg Spine 21: 160-170.

22. Phillips FM, Isaacs RE, Rodgers WB, Khajavi K, Tohmeh AG, et al. (2013) Adult degenerative scoliosis treated with XLIF: clinical and radiographical results of a prospective multicenter study with $24-$ month follow-up. Spine (Phila Pa 1976) 38: 1853-1861.

23. Isaacs R, Hyde J, Goodrich JA, Rodgers WB, Phillips FM (2010) A prospective multicenter evaluation of extreme lateral interbody fusion for the treatment of adult degenerative scoliosis: Perioperative outcomes and complications. Spine 35: S322-330.

24. Hsieh MK, Chen LH, Niu CC, Fu TS, Lai PL, et al. (2015) Combined anterior lumbar interbody fusion and instrumented posterolateral fusion for degenerative lumbar scoliosis: indication and surgical outcomes. BMC Surg 15: 26.

25. Kim HJ, Boachie-Adjei O, Shaffrey Cl, Schwab F, Lafage V, et al. (2014) Upper thoracic versus lower thoracic upper instrumented vertebrae endpoints have similar outcomes and complications in adult scoliosis. Spine 39: E795-799.

26. Scheer JK, Smith JS, Clark AJ, Lafage V, Kim HJ, et al. (2015) Comprehensive study of back and leg pain improvements after adult spinal deformity surgery: analysis of 421 patients with 2-year follow-up and of the impact of the surgery on treatment satisfaction. J Neurosurg Spine 22: 540-553.

27. Fakurnejad S, Scheer JK, Lafage V, Smith JS, Deviren V, et al. (2015) The likelihood of reaching minimum clinically important difference and substantial clinical benefit at 2 years following a 3-column osteotomy: analysis of 140 patients. J Neurosurg Spine 23: 340-348.

28. Bridwell KH (1996) Where to stop the fusion distally in adult scoliosis: L4, L5, or the sacrum? Instr Course Lect 45: 101-107.

29. Edwards CC 2nd, Bridwell KH, Patel A, Rinella AS, Berra A, et al. (2004) Long adult deformity fusions to $L 5$ and the sacrum. A matched cohort analysis. Spine (Phila Pa 1976) 29: 1996-2005.

30. Kuhns CA, Bridwell KH, Lenke LG, Amor C, Lehman RA, et al. (2007) Thoracolumbar deformity arthrodesis stopping at L5: fate of the L5-S1 disc, minimum 5-year follow-up. Spine (Phila Pa 1976) 32: 2771-2776.

31. Bao H, He S, Liu Z, Zhu Z, Qiu Y, et al. (2015) Will immediate postoperative imbalance improve in patients with thoracolumbar/lumbar degenerative kyphoscoliosis? A comparison between Smith-Petersen osteotomy and pedicle subtraction osteotomy with an average 4 years of follow-up. Spine 40: E293-300.

32. Koller H, Pfanz C, Meier O, Hitzl W, Mayer M, et al. (2015) Factors influencing radiographic and clinical outcomes in adult scoliosis surgery: a study of 448 European patients. Eur Spine $\mathrm{J}$ Epub ahead of print.

33. Guler UO, Cetin E, Yaman O, Pellise F, Casademut AV, et al. (2015) Sacropelvic fixation in adult spinal deformity (ASD); a very high rate of mechanical failure. Eur Spine J 24: 1085-1091.

34. Cho KJ, Bridwell KH, Lenke LG, Berra A, Baldus C (2005) Comparison of Smith-Petersen versus pedicle subtraction osteotomy for the correction of fixed sagittal imbalance. Spine (Phila Pa 1976) 30: 2030-2037

35. Moal B, Schwab F, Ames CP, Smith JS, Ryan D, et al. (2014) Radiographic outcomes of adult spinal deformity correction: A critical analysis of variability and failures across deformity patterns. Spine Deformity 2: 219-225.

36. Wang G, Hu J, Liu X, Cao Y (2015) Surgical treatments for degenerative lumbar scoliosis: a meta analysis. Eur Spine J 24: 1792-1799. 